\title{
Awareness and Knowledge of Diarrhoeal Home Management among Mothers of Under-five in Ibadan, Nigeria
}

\author{
Olubunmi Omowumi Olopha*, Bolaji Egbewale \\ Department of Community Medicine, Faculty of Clinical Sciences, College of Health Sciences, Ladoke Akintola University of Technology, \\ Nigeria
}

Copyright $(2017$ by authors, all rights reserved. Authors agree that this article remains permanently open access under the terms of the Creative Commons Attribution License 4.0 International License

\begin{abstract}
Improving maternal and child health care is one of the most utmost priorities of every responsible society. Civilization is adjudged by the level of assistance and help a society renders to its most vulnerable groups. Under-five children constitute an important population group in terms of vulnerability to health conditions that could adversely affect their health and well-being. Diarrhoea disease has been reported to be one of the most common causes of infant deaths especially in the developing countries of the world. Oral rehydration therapy (ORT) with oral rehydration solution (ORS) is the appropriate management of diarrhoeal dehydration and is the single most effective strategy in preventing diarrhoeal deaths in children. The extent to which mothers of under-five children can adopt this therapy is tied to their level of knowledge on its efficacy and preparation. This study was designed to examine awareness and knowledge of ORS in diarrhea home management among mothers of under-five in Ibadan. The cross-sectional descriptive survey was employed in the study and data was generated from households using a self-developed and validated questionnaire. Generated data were analysed using descriptive statistics of frequency counts and percentages. Findings showed that while awareness of ORS in diarrhea prevention was high, knowledge relating to its preparation and use was found to be low. Population-specific intervention to improve knowledge of under-five mothers on diarrhea home management was recommended.
\end{abstract}

Keywords Diarrhoea, Home Management, ORS, Under-five Mothers

\section{Introduction}

Civilizations are adjudged by the level of assistance and care a society can render for its most vulnerable populations.
Childhood stage of development is characterized by near-total dependence by the children on adults and health care services provided by them. Under-five children constitute an important population group in terms of vulnerability to health conditions that could adversely affect their health and well-being. Diarrhoea disease has been reported to be one of the most common causes of infant deaths especially in the developing countries of the world. The United Nation International Children Fund and World Health Organization (UNICEF and WHO) [1] estimated that diarrhoea is responsible for nearly one in five deaths among children (about 1.5 million child's deaths each year) which account for $16 \%$ of all under-five deaths every year. Diarrhoea is the passage of three or more loose or watery stools in a 24-hour period. It can be an increase in daily stool fluidity, frequency or volume from what is considered to be normal for individual. It can be acute or chronic, and may also contain blood as in dysentery. Diarrhoea can result from a wide range of factors, which include infection such as bacterial, protozoa and viral infections, examples are rotavirus, cholera, and typhoid enteritis which are transmitted through the faecal-oral route. It can also be non-infective origin such as dietary indiscretions and problems of mal-digestion and mal-absorption [1].

Available evidence shows that diarrhoea poses a grave health threat to child health and well-being in Nigeria. It has been estimated that more than 194,000 Nigerian children die of diarrhoea annually [2]. 94\% of diarrhoea disease burden in Nigeria has been attributable to the environment and associated with risk factors such as unsafe drinking water, lack of sanitation and poor hygiene [3]. In the same vein, other researchers reported that poor weaning methods which promote bottle feeding and insanitary environment also make the children susceptible to infections [4]. It is also important to report that adherence to superstitious beliefs and traditions and acceptance of incorrect facts with respect to the causes and management of diarrhoea has also contributed immensely to the worrisome burden of diarrhoea 
in Nigeria [4]. Still on factors increasing vulnerability to diarrhoea related death among children, O'Reilly, Jaron, Ochieng, Nyaguara, Tate and Parsons [5] stated that poor nutritional status, dehydration, and lack of breastfeeding are the major risk factors for death from diarrhoea. On the causative factor of the disease, studies have revealed that rotavirus is the most frequent etiological agent of diarrhoeal [6] and of the bacterial infectious agents, Escherichia coli are the major pathogens afflicting children aged less than five years [7].

Most of diarrhoeal episodes are self-limited however the mortality is primarily due to dehydration [8]. In order to fight against dehydration, the World Health Organization (WHO) has, since the 1970s, recommended oral rehydration therapy (ORT) [9]. ORT during bouts of diarrhoea consists of using either a solution prepared from sachets of oral rehydration salts (ORS), or a solution prepared at home with water, sugar and salt, known as the salt-sugar solution (SSS). These are simple, effective, and inexpensive treatments, which have contributed to a significant decline in mortality among children less than five years of age [10]. ORT use experienced a growth rate of $9 \%$ between 1995 and 2010, compared to $30 \%$ growth between 1980 and 1995 [10]. This slowdown has been explained by ignorance of ORT, its widespread misuse, and lack of conviction by medical staff about its effectiveness [11].

Oral rehydration therapy (ort) with oral rehydration solution (ORS) is the appropriate management of diarrhoeal dehydration and is the single most effective strategy in preventing diarrhoeal deaths in children. ORS has been considered as inexpensive and can be easily administered at home by the mothers as soon as a diarrhoea episode begins. Its use has been recommended by World Health Organization (WHO) Homemade sugar and salt solution (SSS) is not quite as good as commercial oral rehydration solution as it does not contain potassium. This therapy is readily available and often lifesaving and death from diarrhoea is easily preventable by this simple therapy. Adequate knowledge in correct measurement techniques are essential for the preparation of oral rehydration solutions but dangerous or ineffective solutions may also result from the inherent variability of the method and ingredients; If the solution has too much salt the child may refuse to drink it. Also, too much salt can, in extreme cases, cause convulsions. Too little salt does no harm but is less effective in preventing dehydration.

Home treatment is an essential part of diarrhoeal management as researchers agreed that it is the hallmark of diarrhoea control programme in Nigeria $[4,12]$. The importance of home management of diarrhoea (which essentially is administration of fluid, use of zinc tablets, correct feeding during diarrhoeal episodes and recognition of time to seek health care) lies on the fact that diarrhoea starts at home, and continues at home on return after being seen at a health facility. Mothers are the key caregivers to under-five children. They are the ones who decide about the type of food given to the child and the overall management of the disease. Therefore, their knowledge about this common disease is critically important. Awareness of management and perception towards diarrhoea, and individual as well as household actions to prevent and/or manage the disease, has paramount importance to reduce diarrhoea-related morbidities and mortalities [13]. On the other hand, mothers' poor knowledge and attitude about the cause of diarrhoea might limit them from taking appropriate timely actions.

According to Uchendu and Emoli [14] a lot of fluid is lost in diarrhoeal stools, and if suitable fluids are given in adequate volumes soon after the onset of diarrhoea and the child is correctly fed, dehydration and nutritional damage can often be prevented. A study by Mellinda [15] on the effect of oral rehydration solution (ORS) and recommended home fluids (RHFs) on diarrhoea mortality showed that ORS may reduce diarrhoea mortality by up to $93 \%$ in home, community and facility settings. However, it is very important to make use of ORS that is correctly prepared. In countries with high-mortality due to diarrhoea such as Nigeria, the prevailing practice among mothers is to seek treatment from private retailers such as pharmacies and drug shops. This is worsened by the risk of unregulated distribution of drugs through the private market, more expensive and ineffective treatments such as antibiotics, analgesics and anti-diarrhoea drugs are being employed when they are not indicated [16].

Similarly, Wessells and Brown [17] also submitted that this problem has increased and has reached enormous proportions, because almost any kind of drug (including antibiotics) can be sold over the counter. The diarrhoeal control programme launched by the WHO in 1978 which was reviewed by UNICEF/WHO through which a joint statement was released in 2004 has stated clearly the guidelines for diarrhoea management with emphasis on oral rehydration therapy, continued feeding during diarrhoea, rational use of drugs and education of parents regarding home management. This study was designed to examine the awareness and knowledge of diarrhoea home management among mothers of under-five in urban and peri-urban locations in Ibadan.

\section{Research Objectives}

The main objective of this study is to investigate awareness and knowledge of diarrhoea home management among mothers of under-five in Ibadan. Specifically, the study aims at investigating and documenting:

1) Awareness level of respondents on diarrhoea home management

2) Knowledge of diarrhoea home management among respondents

\section{Research Questions}

The study provided answers to the following research 
questions:

1) What is the level of awareness of mothers on the use of oral rehydration solution in home management of under-five diarrhoea in Ibadan?

2) What is the level of knowledge of diarrhoeal home management among mothers of under-five children in Ibadan?

\section{Methodology}

The descriptive survey research design of the cross-sectional type was employed in the study because of its suitability in finding answers to the research problem. This design is employed when a researcher is interested in surveying and describing variables of interests and their relationship how they naturally occur without any attempt to manipulate them. Since this study aimed at surveying the level of awareness and knowledge of diarrhea disease among mothers of under-five children, the descriptive survey research design was adopted as the most appropriate design. The target population constituted mothers of under-five in a community based household survey. A sample of 420 respondents was selected for the study using a multistage sampling procedure.. At the first sampling stage, local governments in the study area were stratified into urban and peri-urban strata with each containing five and six local government areas respectively. At the second sampling stage, three LGAs were randomly selected from the two strata to make six LGAs. The third stage involved simple random sampling technique to select two wards from each of the six selected LGAs to make a total of 12 wards. Respondents for the study were drawn at household level by visiting all households in each of the selected wards, surveying mothers or primary care givers of children below five years using the structured questionnaire that has been translated to local language. Any household that did not have children below five years was omitted until 35 mothers/primary care givers were surveyed in each of the 12 selected wards to make 420 in all. The inclusion criterion was having at least one child that is below five years old. The instrument for data collection in the study was a self-developed structured and validated questionnaire with a reliability of 0.78 Cronbach Alpha. The instrument was designed to generate data on awareness and knowledge of diarrhea as well as on knowledge of home management of diarrhea using zinc as well as ORS and SSS. The generated data were analyzed using descriptive statistics of frequency counts and percentages. Ethical approval for the study was obtained from Oyo State Ministry of Health and the fieldwork was conducted for five months with the assistance of seven research assistants.

\section{Results}

\section{Question One}

What is the level of awareness of mothers on the use of oral rehydration solution in home management of under-five diarrhoea in Ibadan?

Table 1. Awareness of ORS in Diarrhoeal Home Management

\begin{tabular}{|l|c|c|}
\hline & Yes & No \\
\hline $\begin{array}{l}\text { Have you heard of oral rehydration solution as } \\
\text { a means of managing childhood diarrhoea at } \\
\text { home? }\end{array}$ & $\begin{array}{c}385 \\
(92.1 \%)\end{array}$ & $\begin{array}{c}33 \\
(7.9 \%)\end{array}$ \\
\hline
\end{tabular}

The table above shows the information about the status of awareness of respondents on the use of ORS in diarrhoeal control. It is evident in this table that a significant percentage (92.1) of mothers stated that they are aware of ORS while only $7.9 \%$ answered 'no' to this question. This level of awareness would only be considered advantageous if it reflects in improved knowledge of ORS preparation as well as in its utilization.

\section{Question Two}

What is the level of knowledge of diarrhoeal home management among mothers of under-five children in Ibadan?

Table 2. Respondents' Knowledge of Diarrhoeal Home Management: Use of Zinc

\begin{tabular}{|c|c|c|c|}
\hline \multirow{2}{*}{ Items } & Variables & Freq & $\begin{array}{c}\text { Percent } \\
\text { age }\end{array}$ \\
\hline \multirow{2}{*}{$\begin{array}{c}\text { Zinc tablet or } \\
\text { suspension is used for } \\
\text { children with diarrhoea: }\end{array}$} & Yes & 136 & 32.5 \\
\cline { 2 - 4 } & No & 29 & 6.9 \\
\hline \multirow{4}{*}{ Zinc is given } & I don't know & 253 & 60.5 \\
\cline { 2 - 4 } & Twice daily & 24 & 5.7 \\
\cline { 2 - 4 } & Thrice daily & 14 & 3.3 \\
\cline { 2 - 4 } & Four times daily & 3 & .7 \\
\cline { 2 - 4 } & I don't know & 306 & 72.3 \\
\hline \multirow{3}{*}{$\begin{array}{c}\text { Zinc is given for } \\
\text { duration of }\end{array}$} & 3days & 31 & 7.4 \\
\cline { 2 - 4 } & 5days & 13 & 3.1 \\
\cline { 2 - 4 } & 7days & 13 & 3.1 \\
\cline { 2 - 4 } & 10-14 days & 45 & 10.7 \\
\cline { 2 - 4 } & I don't know & 316 & 75.6 \\
\hline
\end{tabular}

Findings of the study also reported poor level of knowledge of childhood diarrhoea management in table 3 as only $32.5 \%$ of the respondents rightly indicated that zinc tablet or suspension could be used in managing childhood diarrhoea. 6.9\% erroneously indicated 'no' while the largest proportion of the respondents $(60.5 \%)$ stated that they do not know. Lower level of knowledge was reported on the timing of zinc administration as only $17.0 \%$ of the respondents correctly reported administration of zinc tablet or suspension daily. $5.7 \%, 3.3 \%$ and $0.7 \%$ wrongly stated administration of zinc twice, thrice and four times daily respectively. Moreover, the largest proportion of the respondents $(72.3 \%)$ reported not having knowledge of the timing of administration of zinc. On the duration of zinc administration, only 10-14 days of the respondents correctly reported that zinc is given 10-14 days with the largest 
proportion $(75.6 \%)$ reporting that they do not know the duration of zinc administration.

Table 3. Respondents' knowledge of Diarrhoeal Home management: Use of ORS/SSS

\begin{tabular}{|c|c|c|c|}
\hline Items & Variables & Freq. & Percentage \\
\hline \multirow{5}{*}{$\begin{array}{l}\text { The work of } \\
\text { ORS is to }\end{array}$} & Stop diarrhoea & 114 & 27.3 \\
\hline & $\begin{array}{l}\text { Reduce the duration of } \\
\text { diarrhoea }\end{array}$ & 21 & 5.0 \\
\hline & $\begin{array}{l}\text { Replace the body salts, } \\
\text { energy and water lost } \\
\text { in diarrhoea }\end{array}$ & 215 & 51.4 \\
\hline & Prevents diarrhoea & 3 & .7 \\
\hline & I don't know & 65 & 15.5 \\
\hline \multirow{3}{*}{$\begin{array}{l}\text { ORS is given } \\
\text { with }\end{array}$} & Feeding bottle & 60 & 14.4 \\
\hline & Cup and spoon & 338 & 80.9 \\
\hline & By force feeding & 20 & 4.8 \\
\hline \multirow{4}{*}{$\begin{array}{l}\text { How soon should } \\
\text { the use of } \\
\text { ORS/SSS start }\end{array}$} & $\begin{array}{c}\text { After two days of } \\
\text { watery stool }\end{array}$ & 107 & 25.6 \\
\hline & After three days & 16 & 3.8 \\
\hline & $\begin{array}{c}\text { Soon after the } \\
\text { first/second motion of } \\
\text { watery stool noticed }\end{array}$ & 228 & 54.6 \\
\hline & I don't know & 67 & 16.1 \\
\hline \multirow{6}{*}{$\begin{array}{l}\text { Timing of ORS } \\
\text { administration: } \\
\text { It is given }\end{array}$} & Every hour & 65 & 15.6 \\
\hline & $\begin{array}{l}\text { After each bowel } \\
\text { motion }\end{array}$ & 117 & 28.0 \\
\hline & After vomiting & 9 & 2.2 \\
\hline & $\begin{array}{l}\text { To prevent diarrhoea } \\
\text { before it starts }\end{array}$ & 7 & 1.7 \\
\hline & Frequently & 180 & 43.1 \\
\hline & I don't know & 40 & 9.6 \\
\hline
\end{tabular}

On the knowledge of the purpose of ORS in diarrhoea management, findings showed that the largest proportion (51.4\%); although, a little above $50 \%$ reported that the purpose of ORS is to replace body salts, energy and water lost in diarrhoea. $27.3 \%$ reported that the purpose is to stop diarrhoea, $5.0 \%$ reported that the purpose is for reduction of diarrhoea, $0.7 \%$ reported the purpose for prevention of diarrhoea while $15.5 \%$ stated that they do not know.

On the administration of ORS, the largest proportion of the respondents $(80.9 \%)$ rightly reported that children are given ORS/SSS using cup and spoon. $14.4 \%$ reported the use of feeding bottle while $4.8 \%$ reported the use of forced feeding. On the commencement of ORS administration, the largest proportion of the respondents (54.6\%) correctly stated that ORS should be administered soon after the first/second motion of watery stool. $25.6 \%$ stated that it should commence two days after while $3.8 \%$ reported commencement after three days of noticing watery stool. However, only $43.1 \%$ rightly reported that ORS should be administered frequently. $15.6 \%, 28.0 \%$ and $2.2 \%$ reported every hour, after each bowel motion and after vomiting respectively. $1.7 \%$ reported administration to prevent diarrhoea before its onset while $9.6 \%$ reported that they do not know.

\section{Discussions of Findings}

The result of the study indicated a high level of awareness of ORS in under-five diarrhoea home management. This high level of awareness can be attributable to exposures to information on child care during immunization visits as well as experiences shared among mothers of under-five. Although over $90 \%$ of the respondents indicated being aware of ORS in diarrhoea management, awareness does not translate to knowledge. For the fact that a substantial proportion of the respondents reported awareness of ORS, they might not have scientific and accurate information regarding its preparation and use. However, having a high level of awareness on the existence and probably potency of ORS in home management of childhood diarrhoea is important as this awareness could trigger or stimulate consciousness needed to improve information seeking regarding preparation and use of ORS. When one does not have awareness about a particular therapy, the prospect of seeking more information to deepen knowledge about that therapy would be greatly lowered. With high level of awareness, making effort to seek information that could tilt awareness to knowledge level is enhanced. The findings of the study that reported high level of awareness on the use of ORS in diarrhoea home management support the earlier findings of Osonwa, Eko, and Ema [18] who reported an even higher awareness level (95.5\%) among mothers of under-five children in Calabar, another major Nigerian city. It is also in line with the findings of Olakunle, Odili, Kamaldeen and Buhar [19] who also reported awareness level of over $90 \%$ among their respondents in another study in Nigeria.

Just as envisaged, the result of the study on knowledge of diarrhoea home management showed that the level of awareness on ORS did not translate to high knowledge level of diarrhoea home management using ORS. Although a little above $50 \%$ of the respondents correctly stated that the purpose of ORS in replacing lost solute, water and energy, non-negligible proportion demonstrated lack of this basic knowledge. Moreover, on the administration of ORS, findings showed that about $80 \%$ of the respondents rightly disclosed the use of spoon and cup. In the same vein, another $54 \%$ of the respondents correctly stated the timing of administration of ORS. The result of the study also showed that the largest proportion of the respondents do not have correct knowledge on frequent administration of ORS. In health behaviour, Anyanwu and Okeke (20) noted that knowledge serves as the basis upon which right attitude is built thereby resulting in manifestation of the appropriate health behaviour. The relatively low level of knowledge on ORS and diarrhoea home management is in line with the findings of Macdonald, Moralejo and Mathew [21] who reported low level of knowledge of diarrhoea home management. On the preparation of ORS, findings showed that respondents demonstrated incorrect knowledge. Findings showed that over $82 \%$ of the respondents' demonstrated incorrect knowledge of ORS preparation with 
an even higher percentage (93.1\%) demonstrating incorrect knowledge of preparation of salt-sugar solution (SSS) which is an alternative to ORS. This has great implication for targeted health education to address knowledge gap rather than mere creation of awareness on ORS use in diarrhoea home management.

\section{Conclusion and Recommendations}

From the outcome of the study, it is concluded that although under-five mothers in Ibadan have a high level of awareness of ORS in diarrhoea home management, this awareness level is not reflected in knowledge of ORS preparation and use in under-five diarrhoea management at home. Based on this, the following are recommended:

1) Target health educational programme aimed at improving knowledge of mothers on diarrhea home management using ORS and SSS is strongly recommended

2) Health care providers must tilt health information efforts from mere awareness creation to behaviour-change targeted interventions aimed at empowering mothers with requisite knowledge and skill to identify diarrhea signs and symptoms and rake necessary steps including timely hospital visit

3) The mass media could be put into good use in educating mothers on technical know-how in under-five diarrhoea prevention and home management

4) The use of peer based diarrhoea management education might be considered as potent and effective in disseminating diarrhoea management information to mothers of under-five.

\section{Limitation of the Study}

The major limitation in this study is that it relied on retrospective self-reported information given by the mothers/care givers. Corroborative observational data would have been useful for such things as ORS use.

\section{REFERENCES}

[1] UNICEF/WHO. (2009). Diarrhoea: Why children are still dying and what can be done. NewYork:United Nations Children's Fund.

[2] UNICEF. 2012. Pneumonia and Diarrhoea: Tackling the Deadliest Diseases for the World's Poorest Children. New York: UNICEF;

[3] WHO (2006). Implementing the New Recommendations on the Clinical Management of Diarrhoea: Guidelines for Policy Makers and Programme Managers. Geneva

[4] Ogunrinde O.G, Raji T, Owolabi O.A and Anigo KM. (2011). Knowledge, Attitude and Practice of Home Management of Childhood Diarrhoea among Caregivers of Under-5 Children with Diarrhoeal Disease in Northwestern Nigeria. Journal of Tropic Pediatric. Available from: http://tropej.oxfordjournals.org/content/early. Accessed: April 2015

[5] O'Reilly, C.E., Jaron, P., Ochieng, B., Nyaguara, Tate, J.E. and Parsons, M.B et al., (2012). Risk factors for death among children less than 5 years old hospitalized with diarrhea in rural western Kenya, 2005-2007: a cohort study. PlosMed. 2012; 9(7):e1001256. doi: 10.1371/journal.pmed.1001256. Epub 2012 Jul 3

[6] Sillah F, Ho HJ, and Chao JC. (2013). The use of oral rehydration salt in managing children under 5 years old with diarrhoea in the Gambia: knowledge, attitude, and practice. Nutrition; 29(11-12): 1368-73.

[7] El-Mohammady H, Mansour A, Shaheen HI, Henien NH, Motawea MS and Raafat I (2012). Increase in the detection rate of viral and parasitic enteric pathogens among Egyptian children with acute diarrhea, 6(11):774-81.

[8] Patel A.B, Ovung, R.,Badhoniya, N.B.and Dibley M.J. (2012). Risk factors for predicting diarrheal duration and morbidity in children with acute diarrhea. Indian Journal of Pediatricsr; 79(4):472-7.

[9] WHO (2009). Diarrhoeal disease fact sheet. [Online] Available at http://www.who.int/mediacentre/factsheets/fs33 0/en/index.html. Retrieved 12th March 2016

[10] Santosham M, Chandran A, Fitzwater S, Fischer-Walker C, Baqui AH, Black R, et al. (2013) Progress and barriers for the control of diarrhoeal disease. Lancet. 2010; 376: 63-67.

[11] Essomba N.E., Koum, D.C., Adiogo, D., Ngwe, M.I. and Coppieters, Y. (2015) Use of oral rehydration therapy in the treatment of childhood diarrhoea in Douala, Cameroon,Malawi Med J.; 27(2): 60-64

[12] Ghasemi AA, Talebian A, MasoudiAlavi N, Mousavi GA. (2013). Knowledge of mothers in management of diarrhoea in underfive children, in Kashan, Iran. Nurs MidwiferyStud.; 1: $158-62$.

[13] Othero D. M., Orago A. S., Groenewegen T., Kaseje D.O., Otengah P. A.2008. Home management of diarrhoea among under-five in a rural community in Kenya: Household perception and practices. East African Journal of Public Health; 5(3):142-146.

[14] Uchendu, U.O., and Emoli, I.J. 2007. Pre-hospital management of diarrhoea among caregivers resenting at a tertiary health institution: implications for practice and health education. African Health Sciences 11(1):41-47.

[15] Melinda G. (2006). Oral Rehydration Therapy in Children with Acute Gastroenteritis. . Available from: http://www.accesslibrary.com/coms2/summary_0286-31765 453ITM.J Accessed July, 2015

[16] Waddington, H. Snilstveit, B., White, H, and Fewtrell L. (2009). Water, sanitation and hygiene: interventions to combat childhood diarrhoea in developing countries. New Delhi: International Initiative for Impact Evaluation.

[17] Wessells, K.R. and Brown K.H. (2012). Estimating the global prevalence of zinc deficiency: results based on zinc availability in national food supplies and the prevalence of stunting. PlosOne 7(11): e50568. doi: 10.1371/journal.pone. 0050568. Epub 2012 Nov 29. 
[18] OsonwaKalu O., Eko Jimmy E., Ema S. (2016). Utilization of Oral Rehydration Therapy in the Management of Diarrhoea in Children among Nursing Mothers in Odukpani Local Government Area of Cross River State, Nigeria. American Journal of Public Health Research, 4(1):28-37

[19] Olakunle J. M. Odili V. U., Kamaldeen A. and Buhari M. (2012). Assessment of mothers' knowledge of home management of childhood diarrhoea in a Nigerian setting. IJPRBS; 1(4): 168-184.
[20] Anyanwu, F.C \&Okeke, S.R. (2016). Retooling Assessment Procedures for Skill-based Health Education for Young People in Nigeria: Implications for 21st Century Educational Assessment. Universal Journal of Educational Research 4(1):58-64

[21] MacDonald, E., Moralejo, D.G., and Mathews, M.K. (2007). Maternal Understanding of Diarrhoea - Related Dehydration and its influence on ORS use in Indonesia. Asia-Pacific Journal of Public Health, 19 (1): 34 - 39. 